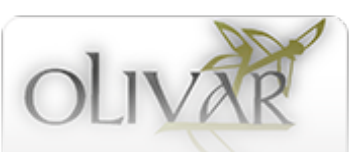

Olivar

ISSN: 1852-4478

publicaciones@fahce.unlp.edu.ar

Universidad Nacional de La Plata

Argentina

\title{
La reescritura del pasado violento y la ficcionalización del presente conflictivo: las narrativas de Edurne Portela e Iban Zaldua
}

Ayerbe Sudupe, Mikel

La reescritura del pasado violento y la ficcionalización del presente conflictivo: las narrativas de Edurne

Portela e Iban Zaldua

Olivar, vol. 19, núm. 30, 2019

Universidad Nacional de La Plata, Argentina

DOI: https://doi.org/10.24215/18524478e061

Esta obra está bajo una Licencia Creative Commons Atribución-NoComercial-Compartirlgual 4.0 Internacional. 


\title{
La reescritura del pasado violento y la ficcionalización del presente conflictivo: las narrativas de Edurne Portela e Iban Zaldua
}

\author{
The rewriting of the violent past and the fictionalization of the present conflictive: the narratives of Edurne Portela \\ and Iban Zaldua
}

Mikel Ayerbe Sudupe

Universidad del Pais Vasco, España

DOI: https://doi.org/10.24215/18524478e 061

\begin{abstract}
RESUMEN:
El análisis de la novela Mejor la ausencia de Edurne Portela y los relatos de Iban Zaldua publicados después del alto al fuego definitivo de ETA remarcan la necesidad de seguir ahondando literariamente en torno a las cuestiones relacionadas con el conflicto vasco, aun cuando el conflicto ha entrado en otro ciclo. Portela opta por ofrecer una revisión del pasado violento mediante una crónica familiar y la reescritura de la misma, mientras que en el caso de Zaldua, los relatos más recientes se sitúan temporal y temáticamente en la denominada era post-ETA.
\end{abstract}

Palabras clave: Literatura vasca, Conflicto vasco, Edurne Portela, Iban Zaldua.

\section{Abstract:}

The analysis of the novel Mejor la ausencia of Edurne Portela and the stories of Iban Zaldua published after the final cease-fire of ETA highlight the need to continue digging literarily around issues related to the Basque conflict, even when the conflict has entered in another cycle. Portela chooses to offer a review of the violent past through a family chronicle and the rewriting of the same, while in the case of Zaldua, the most recent stories are placed temporarily and thematically in the so-called post-ETA era.

KEYWORDS: Basque literatura, Basque conflicto, Edurne Portela, Iban Zaldua.

Este artículo $^{1}$ pretende ofrecer un acercamiento a las narrativas de Edurne Portela e Iban Zaldua, concretamente haciendo hincapié en las propuestas ficcionales que ambos ofrecen en torno al denominado "conflicto vasco". Partiendo de la base de que el conflicto ha entrado en otra fase después del alto al fuego definitivo del 2011 y la disolución de ETA del 2018, hasta el punto en el que se ha empezado a hablar de post-conflicto, hay que tener en cuenta que, aunque la época más violenta ha llegado a su fin, el conflicto en sí todavía no ha terminado. Muestra de ello son las discusiones generadas hoy en día a raíz del "Relato": de cómo hay que contar lo que ha pasado en los últimos 50 años en la sociedad vasca y cómo elaborar un relato consensuado en torno al conflicto vasco. Y aunque, en teoría, la labor de generar ese relato compartido -o esos relatos- depende de la tarea de instituciones políticas, historiadores, sociólogos, educadores, asociaciones y demás, también se ha dado el caso que el "conflicto del relato" ha llegado a copar el ámbito de la literatura, hasta el punto de que, en algunas ocasiones, se ha hablado de "la novela definitiva sobre el conflicto vasco", o la necesidad de una "derrota literaria de ETA". Sin embargo, los autores que presentamos a continuación no persiguen dichos fines, sino utilizar la literatura y la ficción en torno al conflicto para generar más preguntas, ofrecer planteamientos para situar al lector en otro lugar -o en el lugar del otro-, apuntalar, si es preciso, el relato oficial y, en suma, hacer cuestionar todo aquello que podemos presuponer en torno a la sociedad vasca marcada por la violencia, aun cuando la violencia haya llegado a su fin.

Los dos autores son muy diferentes en cuanto a la trayectoria o propuestas literarias, pero también tienen nexos de unión entre ellos. Zaldua es un autor que, en su mayoría, escribe cuentos en euskara desde finales de los 90 y en casi todos sus libros ha incluido relatos en torno al conflicto vasco. Así lo atestigua su reciente recopilación Como si todo hubiera pasado (2018). Además, en el ensayo Ese idioma raro y poderoso (2012) 
dedica dos capítulos a la literatura vasca en torno al conflicto y en artículos más recientes también ha demostrado que la idea de que en euskara no se ha escrito sobre el tema en cuestión es errónea. ${ }^{2}$ Portela, en cambio, de momento ha publicado una única novela en castellano, Mejor la ausencia (2017), que también abarca temas en torno al conflicto vasco, pero anteriormente escribió el ensayo Los ecos de los disparos (2016) donde analiza obras culturales que tratan sobre el conflicto vasco; entre otras, algunos cuentos de Zaldua. A su vez, la mencionada recopilación de cuentos de Zaldua lo prologa Portela.

El planteamiento literario propuesto por ambos también difiere en cuanto a la temática: en la narrativa de Zaldua predomina el enfoque coyuntural y cotidiano a la hora de abordar cuestiones relacionadas con el conflicto, también en la era post-ETA; mientras que Portela ofrece una mirada hacia el pasado y sitúa la novela en las décadas de mayor violencia.

\section{Mejor la ausencia de Edurne Portela: la reescritura del pasado violento}

Después del más que acertado ensayo El eco de los disparos (2016) donde, además de analizar y proponer una lectura crítica de la cultura y memorias creadas a raíz de la violencia vasca, Portela ya introducía breves relatos de ficción en torno al conflicto, en 2017 publicó la novela Mejor la ausencia (Premio 2018 al mejor libro de ficción del Gremio de las librerías de Madrid). Y aunque no se trata de una novela sobre el conflicto stricto sensu, los acontecimientos relacionados con el mismo invaden muchas páginas de la novela, y también la evolución y el desarrollo de más de un personaje. Visitas a los familiares de ETA refugiados en Iparralde (País Vasco francés), las extorsiones como el denominado impuesto revolucionario, las acciones del GAL ${ }^{3}$, las torturas policiales, las amenazas y la presión social, los atentados de ETA, la kale borroka o violencia callejera, la cárcel u otros hechos más cotidianos de una sociedad marcada por el conflicto son algunos de los factores que se narran en la novela.

La trama se centra en la familia de la protagonista/narradora Amaia Gorostiaga y la relación entre la violencia social y la violencia doméstica es uno de los elementos más notorios de Mejor la ausencia. La novela se construye en dos partes bien delimitadas: la primera y más extensa abarca el período entre 1979-1992 y, de manera cronológica y año por año, se vislumbra la evolución de Amaia en el seno familiar, desde los cinco años hasta que cumple los dieciocho y se marcha a Madrid; la segunda parte, en cambio, se sitúa en el año 2009, cuando la protagonista regresa a su pueblo natal, se enfrenta a su pasado y comienza a escribir su historia.

Por otro lado, la caracterización de la voz femenina es crucial en muchos sentidos. Primero, porque el tono y el estilo narrativo se desarrollan a la par que la protagonista se está haciendo mayor, desde una inocencia en la que el lector está obligado a rellenar los huecos que la visión sesgada de la narradora es incapaz de percibir hasta la madurez y el tono directo, incisivo e incómodo que la protagonista va adquiriendo al madurar. Segundo, porque además de ser testigo de la violencia vasca, el paro, el problema de la heroína y otros aspectos que delimitan su entorno, también se convierte en víctima de otro tipo de violencia, como es el caso de la violencia machista y patriarcal que ejerce especialmente su padre con sus palizas y actitudes, así como también de los chicos de su edad que se sobrepasan con ella o incluso el novio. Sin embargo, Amaia no se amedrenta y desarrolla una identidad compleja que, en parte, se nutre de esas violencias para ejercer la propia, por ejemplo, cuando se enfrenta al padre, pero quizás más aún con la madre. No en vano, el consejo que su hermano heroinómano le da cuando ella tiene diez años no es otro que "en esta casa cada uno sobrevive como puede" (Portela, 2017, p. 40), la misma frase que siete años más tarde ella misma repetirá al hermano borroka a modo de defensa. Y es que, Mejor la ausencia es una novela de personajes narrada desde el prisma de Amaia, pero no por ello los demás personajes se muestran de un modo simple o reduccionista: la relación tóxica entre su padre y su madre, el consentimiento y el alcoholismo de la madre, la figura de la abuela materna, las ausencias del padre debido a "sus labores", la muerte del hermano yonki, la radicalización del otro hermano y sus consecuencias, el refugio en los estudios y la huida a Madrid del tercer hermano, como otros personajes que se inmiscuyen en la familia como la asistenta Pili o el policía Carlos, están construidos de una manera 
poliédrica y veraz, más allá de lo que se muestra. Todos ellos giran en torno a la protagonista y marcan su devenir.

La segunda parte se titula "El regreso (2009)". Amaia se ha divorciado, la han despedido de su trabajo de periodista y, tras quince años de ausencia, vuelve de Madrid a su pueblo natal. Se reencuentra con su madre, se niega a visitar y escribir a su hermano que está en la cárcel (aunque sí que estuvo presente en el juicio) y para más desgracia, se enterará de que el padre también ha regresado al pueblo. Al principio, su única intención es escribir una novela negra, quizás otra manera de evadirse de su pasado y de lo que le rodea, al igual que hizo con los libros, la música, las juergas y las drogas en su temprana juventud. Pero el consejo de su mejor amiga no puede ser más certero al pedirle que escriba una crónica sobre lo que ha visto y ha vivido. Al principio ella se niega - "No quiero escribir sobre el rollo vasco" (Portela, 2017, p. 201)-pero enseguida comienza a escribir retazos de su vida y de su familia, basándose en los pasajes que el lector ya conoce, porque en cierta medida ya se han relatado en la primera parte de la novela. Sin embargo, el tono y la perspectiva varían, la crónica se narra en tercera persona y los episodios "reescritos" rellenan los vacíos que en la historia de la Amaia del comienzo solo se sugieren ya que por aquel entonces la narradora no era capaz de entenderlos en su totalidad. De esta manera, la crónica y el ejercicio de memoria de la Amaia actual ofrece una interpretación detallada de los hechos acaecidos, y aunque solo se muestra la punta del iceberg de lo que escribe, es suficiente para dar a conocer por donde irán los tiros de su relato. Además, los pasajes en los cuales Amaia se muestra sumergida en su proceso creativo y memorístico son de una contundencia abrumadora.

A partir de ese momento, Mejor la ausencia se desdobla en una novela que contiene en sí misma otra novela y el elemento metaficcional se convierte en la piedra angular de la narración. Por un lado, se ofrece la biografía de Amaia y, por el otro, la recreación de esa biografía, la reescritura de la misma. El recurso de la metaficción a la hora de acercarse a temas relacionados con el conflicto vasco ha sido una constante en la literatura escrita en euskara (Ayerbe, 2015; Olaziregi y Ayerbe, 2016). Autores como Atxaga, Saizarbitoria, Sarrionandia, Lertxundi, Urretabizkaia, Cano, Mintegi, Apaolaza y Borda han recurrido a la metaficción a la hora de presentar como protagonistas de sus novelas a escritores que escriben una novela homónima, protagonistas que se encuentran sumergidos en el proceso escritural de una novela, novelas epistolares o novelas donde la metaliteratura abunda de una manera espectacular... Y Portela se suma a esa lista con su novela. En todas ellas nos hallamos con preguntas que interpelan directamente al lector, aunque sea de una manera implícita: ¿Cuál es la labor de un escritor en una sociedad marcada por la violencia? ¿Sirve la literatura para abordar la realidad conflictiva? ¿Qué perspectiva se debe adoptar para acercarse a esa realidad? Cuestiones que tal vez no tengan fácil respuesta, pero la ficción o la literatura misma pueden ser una manera, no quizás de responder, pero sí un modo de sugerir más preguntas y ofrecer otros puntos de vista, otros acercamientos, otros planteamientos en torno a esa realidad conflictiva marcada por la violencia. Y la novela Mejor la ausencia de Portela es claro ejemplo de ello. Por medio del ejercicio de memoria y relatando su historia, la protagonista logra elaborar una reescritura del pasado violento y recalca, a su vez, la importancia de la escritura y la literatura para abordar cuestiones relacionadas con la violencia político-social.

\section{Los Relatos de Iban ZaLdua: LA Ficcionalización DEL PRESENTE CONFLiCTIVo}

Zaldua es un experimentado y reconocido cuentista vasco, lo cual queda demostrado en los relatos recopilados en Ipuinak. Antologia bat (2010) [Cuentos. Una antología], provenientes de Ipuin euskaldunak (1999) [Cuentos vascos], Gezurrak, gezurrak, gezurrak (2000; Mentiras, mentiras, mentiras, 2006), Traizioak (2001) [Traiciones], Itzalak (2004) [Sombras] y Etorkizuna (2005; Porvenir, 2007; Premio Euskadi de Literatura). A dicha antología le han seguido los libros de cuentos Biodiskografiak (2011; Biodiscografias, 2015), Idazten ari dela idazten duen idazlea (2012) [El escritor que escribe que está escribiendo], Inon ez, inoiz ez (2014) [Nunca, en ninguna parte] y el reciente Sekula esan behar ez nizkizun gauzak (2018) [Cosas que no debí haberte contado nunca]. 
En otros ámbitos, ha publicado la novela corta Euskaldun guztion aberria (2008; La patria de todos los vascos, 2009) y el cómic Azken garaipena (2011, dibujado por Julen Ribas y que obtuvo el Premio Euskadi de Literatura Infantil y Juvenil) [La Victoria Final], además de los ensayos sobre literatura Obabatiko tranbia (2002) [Un tranvía desde Obaba], Animalia disekatuak (2005) [Animales disecados] y (Euskal) Literaturaren alde (eta kontra) (2016) [A favor (y en contra) de la literatura (vasca)].

Pero Zaldua no solo escribe en euskera. Ha publicado originariamente en castellano el libro de cuentos $L a$ isla de los antropólogos y otros relatos (2002), la novela de ciencia ficción Si Sabino viviría (2005) y el ensayo sobre literatura vasca Ese idioma raro y poderoso. Once decisiones cruciales que un escritor vasco está obligado a tomar (2012, Premio Euskadi de Ensayo en castellano).

Por último, en su muy reciente antología Como si todo hubiera pasado (2018) Zaldua ha recopilado en castellano una selección de 42 relatos previamente publicados en euskara en torno al denominado conflicto vasco a lo largo de sus veinte años de trayectoria como cuentista. La elaboración, y publicación, de esta antología es muy relevante porque denota y pone de manifiesto un claro hecho: los relatos marcados por la ineludible presencia del conflicto vasco se han convertido en un constate en la narrativa de Zaldua. De este modo, en todas las obras del autor encontramos con regularidad más de un relato ubicado en una sociedad marcada por la violencia, el terrorismo y otras consecuencias de la lucha armada. Bien en primer plano como leitmotiv narrativo, o bien como telón de fondo de los hechos que acaecen. Ur Apalategi también lo recalca:

el tema vasco, la Cosa ${ }^{4}$, como él lo denomina (el conflicto vasco), se ha convertido en tema principal de sus obras [...] La imaginación con la que aborda el tema es única, de forma que integra la historia de la evolución del sujeto vasco junto con sus distintos avatares en su discurso literario. (2013, p. 72)

Dicho discurso literario se enriquece, además, con relatos de muy diversa índole en cuanto a estilo se refiere (de igual modo que ocurre con la mayoría de los relatos de Zaldua, traten o no sobre el conflicto). Por un lado, desde una perspectiva donde prevalece el realismo, por el cual el autor pone de manifiesto la complejidad de la sociedad vasca ceñida por la violencia; y gracias a los diferentes relatos aporta una visión caleidoscópica, polifónica y reflexiva en torno al conflicto: personajes que se encuentran en posiciones políticas e ideológicas antagónicas y los consiguientes enfrentamientos cotidianos del día a día; experiencias y testimonios de víctimas y victimarios y la red social cercana a ellos (como los familiares de los presos y de las víctimas), tanto como la otra parte de la sociedad que mira para otro lado. Todos esos elementos se entrecruzan en los relatos de Zaldua ofreciendo reflejos ficcionales de ese espejo roto por el conflicto: "el autor extrae de entre los pliegues contradictorios y equívocos de la política y de las ideologías un sinfín de paradojas narrativas" (Aldekoa, 2004, p. 227). Además de otros relatos con temas más estremecedores como los secuestros, los guardaespaldas, impuesto revolucionario, los atentados, las torturas, los pisos francos, la cárcel, etc. Pero siempre desde una distancia prudente, no en relación a los hechos que se narran sino en el modo de contarlos, mediante una prosa comedida, pero sin eludir los asuntos escabrosos de esa realidad conflictiva. Sin imponer una visión moralizante unívoca, sino ofreciendo al lector espacios para la interpretación, la reflexión y la toma de conciencia.

En contraposición al acercamiento realista, otra de las constantes de Zaldua a la hora de abordar los relatos en torno al conflicto es el uso de elementos fantásticos, incluso de elementos propios de la ciencia-ficción: sueños premonitorios, apariciones de fantasmas y espectros, regresiones en el tiempo (mediante máquinas del tiempo o mediante brujería), alternancia de dimensiones... Se trata de una manera peculiar y muy personal de llevar a la ficción temas relacionados con la violencia vasca y ahí reside la originalidad de su narrativa, o por lo menos una de las originalidades. Sin embargo, lo fantástico no se enfrenta a lo real, sino que amplía esa realidad, se trata de otro modo de abordarla: "Lo fantástico en sus cuentos revela lo real [...] Incluso cuando toman el camino de la fantasía, los cuentos de Zaldua destilan realidad y verdad” (Portela, 2018, p. 10).

En más de una ocasión ha manifestado Zaldua que sus relatos en torno al conflicto son testimonios que se ciñen a la realidad más cercana, a los sucesos socio-políticos que mayor repercusión han tenido en el 
momento en que estaba escribiendo. Porque Zaldua ha escrito sus relatos sobre el conflicto desde el conflicto. Se trata de un ejercicio de memoria literaria coyuntural, ya que el autor escribe sobre los acontecimientos del momento para intentar entender esa realidad conflictiva que le rodea. No significa que los hechos del pasado no adquieran relevancia, pero lo cierto es que prevalecen los cuentos relacionados con hechos coetáneos.

Esa peculiaridad se percibe perfectamente en la antología Como si todo hubiera pasado. Los relatos siguen el orden cronológico en el que fueron apareciendo desde 1999 hasta 2018 pudiéndose vislumbrar la evolución y el desarrollo de algunos incidentes relacionados con la realidad vasca: las alusiones a atentados concretos, las menciones de las distintas treguas de ETA, las diferentes circunstancias electorales, entre otros, marcan las coordenadas espacio-temporales de los cuentos. También es verdad que la antología ofrece, en cierta medida, una retrospectiva a la historia más próxima de los últimos años, pero precisamente es en los últimos relatos de la recopilación donde se aprecia la perspectiva coyuntural más actual de los cuentos antes mencionada. El título de la antología, tanto como la imagen de la portada -un operario de limpieza borrando una pintada donde dice GORA ETA) -, hacen alusión a la nueva era post-ETA.

\section{EL AHORA “DEL DESPUÉS”}

La literatura vasca del post-ETA está delimitada por el anuncio de la tregua permanente, general y verificable y el posterior cese definitivo de la actividad armada de ETA, tres días después de la Conferencia de Paz de San Sebastián celebrada en Aiete, el año 2011. Las obras que abordan la violencia vasca publicadas tras a esa fecha se enmarcan dentro de ese calificativo del "después”, aunque la mayoría de las propuestas literarias se limitan a rememorar y revisitar cuestiones relacionadas con lo "anterior al final" del conflicto. Sin embargo, la narrativa de Zaldua también es una excepción en ese aspecto, ya que su costumbre de escribir sobre la más candente actualidad le ha llevado a ficcionalizar también los acontecimientos que definirán ese "después" cuando realmente todavía eran el "ahora".

A este respecto, la parte central del libro Inon ez, inoizez [Nunca, en ninguna parte] $]^{5}$ se titula, en oposición, Hemen, orain (2006-2014) [Aquí, ahora (2006-2014)], en la cual se incluyen trece relatos determinados por la violencia vasca escritos entre esos años. El periodo que abarcan los cuentos es la continuación del periodo donde acababan los relatos de Porvenir, que ya con cierta ironía el autor subtituló Diecisiete cuentos casi políticos. Y es curioso que uno de los epígrafes del apartado Hemen, orain(2006-2014), junto con una breve cita de la canción de The Chameleons "Here. Today", casi homónima al título de la sección, sea este de G.K. Chesterton: "Uno de los extremos más necesarios y más olvidados en relación con esa novela llamada Historia, es el hecho de que no está acabada”. Es precisamente ahí donde pone el foco Zaldua, en la inmediatez inacabada, en el aquí y el ahora que más pronto que tarde se convertirá en el ayer y, quizás, en parte de la Historia, pero desde el presente difícilmente se puede vislumbrar aquello que perdurará. De este modo, dos de los títulos de esta sección hacen referencia explícita a dos hechos que hoy en día se pueden calificar como históricos: "Orokorra, iraunkorra, egiaztagiria" ["Permanente, general, verificable"] y "Zer deritzozu ETAk jarduera armatua utzi izanari? Zein neurritan iruditzen zaizu gaurkoa egun historikoa?” “¿Qué te parece que ETA haya anunciado el fin de la lucha armada? ¿En qué medida te parece lo de hoy un día histórico?].

El primer relato se sitúa pocos días después del alto al fuego permanente, general y verificable de ETA, anunciado el 10 de enero de 2011. La historia se centra en el diálogo post-coital de dos amantes, con una apreciable diferencia de edad y de modo de vida. No se muestra otra cosa que un momento concreto de la cotidianeidad entre ambos y el anuncio del alto al fuego se convierte así en otro motivo de conversación como tantos otros, aunque sí que se recalcan las contrarias reacciones ante un hecho que podría marcar el devenir del conflicto vasco. El hastío y la esperanza, la pesadumbre y la emoción, el escepticismo y la ilusión van de la mano en este relato realista. Y es que, en muchos relatos sobre la Cosa de Zaldua, la actualidad se plasma no de una manera sobrecargada o abrumadora, sino mediante pequeños detalles y anécdotas del día a día, que es 
el modo por el cual se construye realmente la realidad, y para ello, muchas veces los protagonistas son seres anodinos o meros ciudadanos de a pie que tienen que pervivir con un entorno empapado por el conflicto.

El segundo relato lleva por título dos preguntas relacionadas directamente con el anuncio del cese definitivo de la actividad armada de ETA, que tuvo lugar el 20 de octubre del 2011. Esas dos preguntas que componen el título -¿Qué te parece que ETA haya anunciado el fin de la lucha armada? ¿En qué medida te parece lo de hoy un día histórico?- las formula un periodista al entrevistar a una viuda que años atrás ETA asesinó a su marido. La respuesta de la víctima es contundente: para ella es un día como cualquier otro, y añade que no va a cambiar nada hasta que llegué la disolución definitiva de ETA, la entrega de las armas y la petición de perdón por todo el sufrimiento causado. Seguidamente llegan más preguntas y respuestas en torno al perdón y el atentado contra su marido y la protagonista revive y relata el fatídico día del asesinato, eso sí, sin mencionar el secreto íntimo relacionado con aquel día. En este caso también se plantea una concreta reacción ante un hecho histórico como es el cese de la actividad armada de ETA, pero la víctima difícilmente acepta dicho anuncio como tal. Además, y al contrario que en el relato anterior, esta vez el lector se acerca a la realidad compleja de una víctima del terrorismo.

Dichos relatos abordan desde el título dos momentos clave en el arranque de la era post-ETA. Pero no son los únicos. El cuento que está entre ambos, "Kanpainaren amaiera" ["Final de la campaña"], narra la relación de dos nacionalistas que históricamente han sido simpatizantes de diferentes partidos políticos nacionalistas pero que a raíz de la nueva coalición política $\mathrm{Bildu}^{6}$ acaban militando y haciendo campaña juntos para las elecciones del mayo del 2011. Pero también deberán enfrentarse a otros fantasmas del pasado relacionados con la violencia heredada, la de sus padres.

De este modo, se puede concluir que estos tres cuentos crean una cronología de los tres acontecimientos relevantes del año 2011, que por un lado culminaron con el final de la violencia armada de ETA y por otro, vaticinaron el giro político en el que ha devenido la Cosa.

\section{EL DESPUÉS “DEL DESPUÉS”}

Sin embargo, la Cosa no se acaba ahí: aunque ha concluido el aspecto más cruel del conflicto, el conflicto en sí no ha concluido. Y así lo recalcan los cuentos de Zaldua que escribe durante los años posteriores: cuestiones en torno a los presos, la memoria de las víctimas y la definición misma de víctima, la construcción del relato y el deber de enfrentarse a los fantasmas del pasado, entre otros, son los ejes centrales de la más reciente narrativa del autor que se incluyen en la antología Como si todo hubiera pasado.

En el cuento titulado "A89, La Transeuropéenne", dos familiares de sendos presos encarcelados en la misma prisión en Francia, se ven en la obligación de compartir el coche. En el coche suena la canción repetitiva "Autobahn" de Kraftwerf y el narrador/copiloto no entiende al conductor, ya que este no hace más que discutir de política con su primo preso, y sin embargo entre ellos nunca han hablado del tema, "ni siquiera después de que la izquierda abertzale y el colectivo de presos cambiaron de estrategia y las cosas se pusieron algo más tranquilas" (Zaldua, 2018, p. 184). El final del relato es alegóricamente fantástico, ya que el conductor aduce que han tenido un accidente, que han entrado en bucle y que realmente cree que están muertos, desde hace tres horas o tres meses y siguen viajando hacia la nada. El copiloto se niega a creerle, pero las repeticiones (la música, las conversaciones) adquieren un nivel espectral y el relato acaba de manera parecida a como ha empezado, repitiéndose casi las mismas palabras del principio.

La cuestión de los familiares que visitan los presos repartidos por todo el estado español y francés a causa de la política de dispersión carcelaria ya aparece en un relato anterior titulado "La Mancha". Se trata de una revisión de la leyenda urbana de la autoestopista fantasma, en este caso la mujer de la curva es una madre que falleció en un accidente al ir a visitar a su hijo preso, que también ha perdido la noción del tiempo y deambula alrededor de la cárcel de Herrera de la Mancha. De este modo, “A89, La Transeuropéenne” retoma y repite algunos de los elementos de "La Mancha" para volver a hablar de las consecuencias trágicas de la dispersión 
para los familiares de los presos y abordar el tema del acercamiento de los presos a las cárceles del País Vasco, una petición que ha cobrado mayor fuerza y respaldo social desde el cese definitivo de la actividad armada de ETA.

Otro de los ejes que Zaldua plantea en los relatos ambientados en la era post-ETA es la necesidad de recordar y la obligación de revisar el pasado, de hacer un ejercicio de memoria, frente a la precipitada posición de pasar página y caer en el olvido. El relato "Como si nada hubiera pasado", de donde procede parafrásticamente el título de la compilación, trata justamente sobre ello. En 2016, y después de trece años sin verse, Eli ve a Ander sentado en la terraza de un bar y no sabe si acercarse a él o no. Seguidamente se resume la historia de ambos de los últimos 30 años, rememorando tres discusiones cruciales que tuvieron a raíz de diversos hechos relacionados con el conflicto, en sentido cronológico inverso: el atentado contra el jefe de policía municipal de Andoain Joseba Pagazaurtundua en el 2003; los secuestros de Aldaya y Ortega Lara en 1996; y por último, el asesinato de Dolores González Katarain Yoyes en 1986, exdirigente de ETA asesinada por la misma organización por traidora. Otros temas también salen a relucir en esas discusiones: el asesinato del periodista José Luis López de la Calle y el cierre del periódico Euskaldunon Egunkaria; las concentraciones en silencio de Gesto por la Paz y las contramanifestaciones; y, por último, las acciones de GAL. En ese breve recorrido, se percibe en la protagonista una reafirmación ideológica para hacer frente a la posición de Ander, quien justifica la violencia. Así, si en la discusión más antigua al final no supo que responder, diez años más tarde ella no da su brazo a torcer encarándose a Ander y en la discusión más reciente, el acercamiento entre ambos es ya imposible. Es por ello que Eli no sabe si en estos tiempos nuevos acertaría a entablar una conversación con él y se imagina acercándose a él para acabar hablando del asunto, escuchando de la mano de Ander que él siempre ha estado en contra de la violencia y a favor del proceso de paz, para después ella admitir que hubo un tiempo en el que ella sí que estuvo a favor de la violencia y es por ello que se avergüenza de todo lo pasado. Sin embargo, resulta que a final del cuento decide no acercarse a él y, tal y como el título presagia, hacer como si nada hubiera pasado. Aun así, el título también hace mención a esa negación del revisionismo del pasado reciente que algunos pretenden, esa huida hacia delante sin mirar atrás. Además de hacer hincapié en la necesidad de ser sinceros con el posicionamiento ideológico que cada cual haya tenido a lo largo de los años. Es por ello que el ejercicio de sinceridad de la protagonista resulta más difícil y compleja, pero más veraz si cabe.

Por lo tanto, al final dicho encuentro no llega a producirse y el relato concluye con la imposibilidad de diálogo entre ambos. Es un tema que encontraremos en más de un relato de Zaldua, lo hemos visto en la mencionada "A89, La Transeuropéenne" y también es el tema central del relato "Gaurkoan esan egingo diot" ["Hoy se lo voy a decir"] de Inon ez, inoiz ez, donde el protagonista va a visitar a un amigo preso con la férrea intención de discutir sobre política y, más exactamente, para echarle en cara las últimas estrategias de ETA, pero cuando llega la ocasión acaban hablando de futbol. El silencio puede ser un mecanismo de defensa, pero también alimenta el tabú y estos cuentos de Zaldua subrayan el silencio para desacralizarlo y abogar por un diálogo que no siempre resulta cómodo.

En cambio, en los tres últimos cuentos de la recopilación "Testimonio", "En el bar de enfrente" e "Itinerario" impera lo fantástico y la ciencia ficción. En el primero, encontramos el testimonio de "un peón", un ex-militante de ETA que a su parecer y con sus declaraciones viene a enriquecer la literatura memorística de los fundadores de ETA Txillardegi o Madariaga e, incluso las autobiografías de Mario Onaindia. El protagonista, nacido en un entorno de la izquierda abertzale, admite que ya pertenecía a ETA cuando la policía mató a Txabi Etxebarrieta -quien asesinó antes a José Pardines, la primera víctima mortal de ETA, en 1968- y que hacía pequeños trabajos como labores de vigilancia. Poco a poco, empieza a hablar de sus "capacidades" y cómo después del Juicio de Burgos, escondido en un piso franco, se percató que tenía un don especial: hacer desaparecer las cosas que miraba fijamente. Acto seguido, la organización decide mandarlo a Alemania para que le hagan pruebas científicas y experimentar con su habilidad y después de hacer desaparecer a un espía norteamericano, decide regresar al País Vasco. La sorpresa llega cuando, la organización 
prescinde de sus capacidades, dado que "para nuestros objetivos, no eran de ninguna utilidad unas acciones que no iban a dejar rastro. Que el enemigo debía de saber quién era el responsable; que tenía que sentir dónde le escocía la herida. Y el pueblo también, claro está" (Zaldua, 2018, p. 239). Seguidamente, el protagonista relata las dos únicas ocasiones que utilizó sus poderes: en 1976 contra Pertur y en 1980 contra Naparra. El declarante era consciente que ambos pertenecían a la misma organización y siembra la duda sobre de quién recibió la orden, si de algún mando superior o si de algún policía infiltrado.

Desde un comienzo, el relato en sí adquiere tintes de una historia de superhéroes con ingredientes tales como pruebas científicas, entrenamientos y hasta la desaparición del espía americano. Pero esa visión confluye con la crudeza real del conflicto armado, primero con las estrategias de la banda armada y segundo, con dos de los episodios más oscuros dentro de ETA: las desapariciones de Eduardo Moreno Bergaretxe Pertur y José Miguel Etxeberria Naparra, cuyos paraderos aún se desconocen; barajándose diferentes versiones e hipótesis, desde que fueron asesinados por sus compañeros de ETA o que fueron víctimas del terrorismo del Estado. El cuento de Zaldua, aun siguiendo un guion de historieta de cómic, pretende apuntar la premisa de la necesidad de esclarecer los sucesos que todavía siguen sin resolverse. Y la época actual debería ayudar a ello, a enfrentarnos a testimonios del pasado. Hay que tener en cuenta, por ejemplo, que alrededor de 300 asesinatos de ETA siguen sin ser resueltos del todo, según un informe que elaboró la fiscalía de la Audiencia Nacional en enero del 2017.

"En el bar de enfrente" se publicó originariamente en euskera en el periódico Berria el 8 de mayo de 2018 dentro de la serie titulada "Creando el final", donde durante la semana del 7 al 13 de mayo se publicaron diversos poemas, cuentos, textos y reproducciones de obras de autores vascos creados a raíz del comunicado que anunciaba la disolución de ETA del 3 de mayo de 2018. En esas coordenadas exactas, y a escasos días del anuncio, Zaldua elabora un relato donde el protagonista, algo aturdido, entra a un bar. Esta desorientado, pide una cerveza, pregunta por el teléfono del bar o por una cabina, y tras las respuestas atónitas del camarero, presta atención a las imágenes de la televisión que versan sobre el final definitivo de ETA y de las sucesivas reacciones. Acto seguido, lo fantástico y fantasmagórico emerge desde la pantalla, al confirmarse la noticia que las víctimas de ETA Gregorio Ordoñez, Yoyes y otros asesinados han resucitado y reaparecen en el mismo lugar y con la misma edad que tenían en el momento de su muerte, y que "el primer regreso, el de M. A. Blanco, se produjo en el instante en que se oficializó la disolución de ETA" (Zaldua, 2018, p. 245). El protagonista del cuento se percata a través de un calendario del año exacto en el que se encuentra, y después de dejar unas pesetas encima de la barra, sale huyendo. Es entonces cuando se descubre la personalidad del protagonista, el padre del camarero le reconoce y rememora que se trata del hombre que murió hace años delante del bar, cuando le explotó una bomba que estaba manipulando que iba a poner contra un concesionario. Al final del relato, la única clienta del bar pide que, por favor, bajen la música y suban el volumen de la televisión, ya que van a dar el parte del tiempo.

Se trata de otro relato espeluznante que cuestiona que, aunque con la disolución de ETA se acaba con lo más atroz y sangriento, el conflicto en sí no concluye y se reabren otros conflictos que ya perduraban desde antes. Por un lado, la memoria sobre las víctimas, pero también la cuestión de las muertes y los asesinatos, y el por qué y para qué de los mismos. En este caso, Zaldua vas más allá y, junto con las víctimas de ETA reaparecidas, hace resurgir al protagonista que iba a estallar una bomba, remarcando así el sinsentido de la violencia y el absurdo de, además de matar, morir por una causa. ¿Acaso se trata de otro tipo de víctima, pero una víctima al fin y al cabo? En todo caso, después del asombro inicial ante lo acontecido, los personajes retoman enseguida sus rutinas diarias y el parte del tiempo adquiere más importancia que las noticias de los extraños sucesos, mostrándose la indiferencia que parte de la sociedad vasca mostró ante tan importante noticia.

Por último, el relato "Itinerario" que cierra la antología de cuentos se ubica en un futuro no muy lejano y aborda la cuestión inmanente a la era post-ETA, la construcción y transmisión del denominado Relato. Un tema de candente actualidad y no exento de disputas, hasta tal punto que podría hablarse del "conflicto 
sobre el relato". Para ello, Zaldua recurre a la ironía y de la mano del protagonista que es guía turístico en San Sebastián, expone dos itinerarios memorísticos paralelos y antagonistas (Memoria A-5 y Memoria B-2): en uno se muestran escenarios y se recrean de modo virtual incidentes relacionados con la visión memorística más acorde a la perspectiva de la izquierda abertzale y en la otra, predominan los lugares de la memoria de atentados de ETA y escenarios donde se hacían las concentraciones silenciosas de repulsa del terrorismo de ETA. Además, en ambos recorridos se mencionan dos obras literarias: 100 metro de Ramon Saizarbitoria y Patria de Fernando Aramburu, respectivamente. Con estos elementos donde la sutil ironía converge con una lógica locuaz, el relato de Zaldua pone en evidencia la crítica sobre el utilitarismo y las visiones unívocas que prevalecen en el discurso interesado sobre el relato que, en algunos casos, se pretende elaborar. Ejemplo de ello es un detalle, ya que en el recorrido Memoria A-5 se menciona que visitarán el escenario de la primera víctima mortal de ETA en 1960, la niña Begoña Urroz, cuando es bien sabido y está probado que ETA no tuvo nada que ver con ese asesinato y el atentado fue perpetrado por el grupo armado del DRIL (Directorio Revolucionario Ibérico de Liberación). Aun así, la manipulación de ese hecho en concreto denuncia las posibles e hipotéticas falsificaciones que se pueden construir sobre dicho relato de la memoria. Por otro lado, las nomenclaturas de los itinerarios dejan entrever que pueden existir más itinerarios con otras letras o números, aunque bien es cierto que el cuento se concentra en esas dos versiones opuestas: A vs. B. Sin embargo, la crítica más negativa que ofrece "Itinerario" es la posible banalización y turistificación de la memoria que se plantea.

\section{A MODO DE CONCLUSIÓN}

A pesar de la brevedad del análisis de los textos ofrecidos, se ha querido resaltar, por un lado, la convincente y necesaria revisión de los tiempos pasados que Portela plantea en la novela Mejor la ausencia, subrayando el aspecto metaficcional de la de la misma. La reescritura de la crónica íntima y familiar que la protagonista elabora permite incidir en el hecho de la necesidad de los testimonios, de escribir sobre aquello que se ha vivido y silenciado y, en definitiva, sobre la importancia de la memoria. Por otro lado, hemos podido comprobar que las constantes de la narrativa de Zaldua sobre La Cosa siguen vigentes también en los relatos ambientados en la era post-ETA: la mezcla del enfoque realista con lo fantástico, el predominio de la actualidad y lo coyuntural desde la cotidianeidad y, en resumen, continuar ofreciendo una panorámica compleja y caleidoscópica de los diferentes sucesos y percepciones sobre el conflicto contemporáneo. Además, el género literario del cuento permite al autor crear una multiplicidad de visiones y voces a la hora de relatar distintos enfoques relacionados con el conflicto. Y aunque, en parte, el compendio de los 42 relatos de Como si todo hubieran pasado se puede leer como si de una novela sobre el conflicto se tratara, lo cierto es que en realidad abarca dimensiones que una novela difícilmente puede tratar. Y lo mismo ocurre con los relatos que se ubican en la reciente era postETA, ya que la narrativa de Zaldua es de las pocas excepciones que ofrece una crónica ficcional en la cual se relata desde el presente lo que ocurre en el presente inmediato.

\section{BiBLIOgRAFíA}

Aldekoa, Iñaki (2004). Historia de la literatura vasca. Donostia-San Sebastián: Erein.

Apalategi, Ur (2013). La evolución romanesca del sujeto vasco: negociaciones literario-ideológicas entre la estrategia de diferenciación y el deseo de homologación. $452^{\circ} \mathrm{F}$. Revista electrónica de teoría de la literatura y literatura comparada, 9, 56-77.

Ayerbe, Mikel (2015). Work in conflict: (Meta)literatura y escritura en novelas que abordan el conflict vasco. En María José Ezeizabarrena \& Ricardo Gómez (Eds.), Eridenen du zerzaz kontenta: Sailkideen omenaldia Henrike Knörr Irakasleari (1947-2008) (pp. 97-112). Bilbao: Universidad del País Vasco. 
Olaziregi, Mari Jose, y Ayerbe, Mikel (2016). El conflicto de la escritura y la rescritura de la identidad: análisis de la narrativa de escritoras vascas que abordan el conflicto vasco. En Katarzyna Moszczynska-Dúrst, Karolina Kumor, Ana Garrido, y Aranzázu Calderón (Eds.), Identidad, género y nuevas subjetividades en las literaturas hispánicas (pp. 45-66). Varsovia: Universidad de Varsovia-Instituto de Estudios Ibéricos.

Portela, Edurne (2017). Mejor la ausencia. Madrid: Galaxia Gutenberg.

Zaldua, Iban (2014). Inon ez, inoiz ez. Donostia-San Sebastián: Elkar.

Zaldua, Iban (2018). Como si todo hubiera pasado. Madrid: Galaxia Gutenberg.

\section{Notas}

1 Esta publicación forma parte de los proyectos US 17/10 (UPV-EHU) y FFI2017-84342-P (MINECO) que desarrolla el grupo de investigación Memoria Histórica en las Literaturas Ibéricas (IT 1047-16).

2 Recomendamos los artículos publicados en el semanario on-line CTXT titulados "Paseo por la zona negativa (I)" y "Paseo por la zona negativa (II)" donde Zaldua ofrece una pormenorizada selección de autores y obras escritas en euskara en torno al conflicto.

3 Los Grupos Antiterroristas de Liberación (GAL) fueron grupos parapoliciales que perpetraron lo que se ha llamado terrorismo de Estado o "guerra sucia" ETA y su entorno, especialmente en Iparralde.

4 "La Cosa" es otro eufemismo para sintetizar y referirse al también eufemístico "conflicto vasco". Y parece que con ese eufemismo no se pretende eludir la complejidad del asunto, sino hacerla más visible y más cercana quizás, pero desde la distancia de la ironía. Ya que la Cosa significa muchas cosas en la narrativa de Zaldua.

5 Algunos relatos de este libro están recogidos en la antología Como si todo bubiera pasado, pero no la mayoría, ya que el autor tiene apalabrada una futura traducción al castellano con la editorial Páginas de Espuma.

6 El desarrollo y los cambios de algunos partidos políticos ha sido otro constante del devenir del conflicto. Después de la ilegalización del partido político Batasuna en el 2003 por la Ley de Partidos, la denominada izquierda abertzale no tenía opción a ninguna representación en las instituciones vascas. Una vez que se negó el registro del partido Sortu por parte del Tribunal Supremo en marzo del 2011, EA y Alternatiba, junto con otros representantes de la izquierda abertzale, crearon la coalición Bildu.

\section{BY-NC-SA}

